\title{
Modelagem e Integração Geofísica (HTEM, Magnetometria e Gamaespectrometria) no Greenstone Belt Rio das Velhas, Quadrilátero Ferrífero, MG
}

Marco A. Couto Jr., Orivaldo F. Baltazar, Raianny C. R. Ferreira, Marcelo S. Marinho, Joanna C. S. Araújo, CPRM - Serviço Geológico do Brasil

Copyright 2016, SBGf - Sociedade Brasileira de Geofísica

Este texto foi preparado para a apresentação no VII Simpósio Brasileiro de Geofísica, Ouro Preto, 25 a 27 de outubro de 2016. Seu conteúdo foi revisado pelo Comite Técnico do VII SimBGf, mas não necessariamente representa a opinião da SBGf ou de seus associados. É proibida a reprodução total ou parcial deste material para propósitos comerciais sem prévia autorização da SBGf.

\section{Abstract}

This paper presents some results of HTEM (Helicopter Transient Electromagnetic) and magnetometry geophysical modeling/inversion and their integration with radiometric data in the Quadrilátero Ferrífero area, MG, Brazil. The HTEM survey identified 898 conductors, with many of them close to mineralized gold zones and strongly correlated to structural and geophysical lineaments, which could indicate the structural control of sufidation zones. The geophysical modeling was focused on two areas: the Lamego and Roça Grande gold deposits. The results showed that the conductors main dip direction towards to SE and seems to indicate the structural configuration of the mineralized bodies with their enclosing rock.

\section{Introdução}

O Quadrilátero Ferrífero (QF) é uma província metalogenética de classe mundial, com importantes depósitos de ferro e ouro. Devido à relevância econômica do QF, com o intuito de fomentar a exploração mineral na área, a CPRM - Serviço Geológico do Brasil executou um aerolevantamento geofísico dos métodos HTEM e magnetometria na porção central do QF, sobre o Greenstone Belt Rio das Velhas, nos anos 2010-2011.

O método HTEM vem sendo empregado na exploração mineral em todo o mundo desde o início dos anos 2000 e tem obtido bons resultados em identificar corpos mineralizados em zonas de sulfetação, seja disseminada ou maciça (Allard, 2010). Entretanto, em muitas situações de depósitos que possuem encaixantes condutivas, pode haver ambiguidade na interpretação da resposta do HTEM, causando dificuldade para distinguir zonas sulfetadas mineralizadas e sua rocha encaixante. Muitos depósitos de Au do QF se encontram desta forma, em que as mineralizações auríferas são do tipo stratabound entre suas encaixantes, formadas por xistos grafitosos e formações ferríferas bandadas (FFBs). Dependendo da situação, o xisto grafitoso, bom condutor, pode prevalecer na resposta do HTEM em relação às zonas mineralizadas.

Para tentar diminuir essa ambiguidade na interpretação dos dados de HTEM, em muitos casos, deve ser feita a integração com dados de outros métodos geofísicos, como a magnetometria e a gamaespectrometria. Estes dois métodos podem ajudar a mapear as zonas de alteração hidrotermal e sua relação com a sulfetação e também com as rochas encaixantes. No caso do QF, a magnetometria pode ajudar a mapear as FFB e a gamaespectometria pode identificar as zonas de enriquecimento potássico, comumente associadas à percolação de fluidos hidrotermais mineralizantes.

Este trabalho faz parte do projeto em desenvolvimento da CPRM, intitulado "Arcabouço Tectônico e Metalogenia do Quadrilátero Ferrífero" e concentrou-se na Área Piloto (AP) deste projeto (Figura 1). Foi feita a integração de dados geofísicos (HTEM, gamaespectrometria e magnetometria) e também a modelagem de condutores identificados pelo HTEM e corpos magnéticos mapeados pela magnetometria.

\section{Metodologia/ Problema Investigado}

A área dos aerolevantamentos analisados localiza-se na região do Quadrilátero Ferrífero, estado de Minas Gerais, e compreende as rochas do Supergrupo Rio das Velhas. Há dois aerolevantamentos por helicóptero nesta área: Rio das Velhas - Etapa I (RV1), que compreende dados de magnetometria, gamaespectrometria e eletromagnético do domínio da frequência (HFEM), espaçamento de linhas de voo de $250 \mathrm{~m}$, e Rio das Velhas - Etapa II (RV2), que compreende dados de magnetometria e eletromagnético do domínio do tempo (HTEM), com espaçamento das linhas de voo de $500 \mathrm{~m}$. Neste trabalho, em relação aos dados eletromagnéticos, por enquanto, foram analisados apenas os dados HTEM do aerolevantamento RV2.

O aerolevantamento HTEM identificou 898 condutores em toda sua área de execução. Muitos destes condutores ocorrem próximos às mineralizações auríferas de modo que, possivelmente, podem estar associados às zonas de sulfetação correlacionadas às mineralizações. Além disso, grande parte dos condutores possui forte controle estrutural e correlaciona-se muito bem com trends magnéticos, extraídos das derivadas, Amplitude do Sinal Analítico (ASA) e Inclinação do Sinal Analítico (ISA) e também trends gamaespectrométricos (lineamentos potássicos e anomalias de Fator F). O mapa apresentado na Figura 1 mostra a localização dos projetos RV1 e RV2 e a posição dos condutores HTEM identificados.

Foi feita a modelagem direta e inversão de alguns corpos magnéticos, nos softwares Encom Model Vision (modelagem direta) e o módulo Voxi do Geosoft Oasis Montaj (inversão magnetométrica). Os condutores HTEM foram modelados diretamente como placas condutoras (placas de Maxwell) no software EMIT Maxwell. Esta 
etapa do trabalho concentrou-se na região da AP (Figura 1). especificamente nas regiões dos depósitos de Lamego (propriedade da AngloGold Ashanti) e Roça Grande (propriedade da Jaguar Mining).

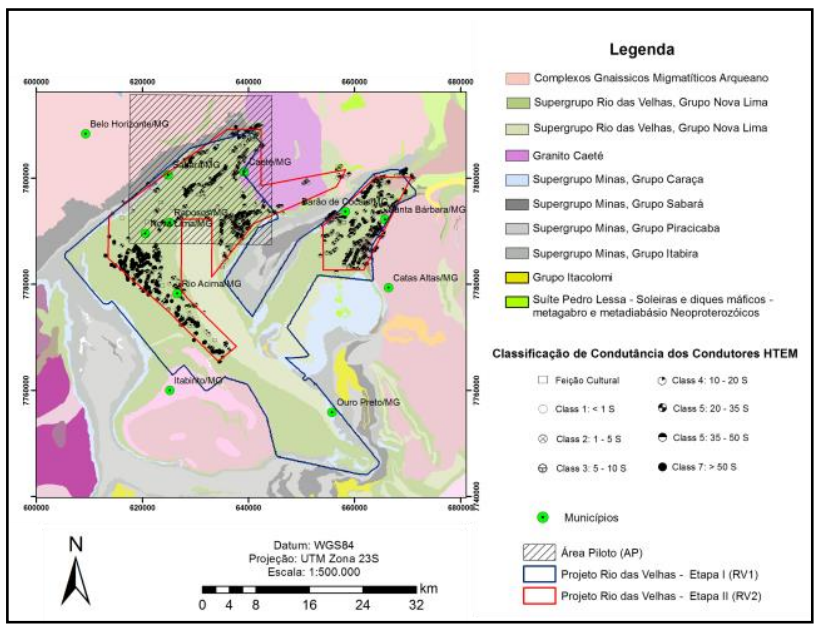

Figura 1 - Mapa de localização dos projetos aerogeofísicos RV1 e RV2 e Área Piloto.

\section{Resultados}

Área Piloto

A Figura 2 apresenta mapas temáticos de geofísica, mapa geológico-estrutural e sua correlação com os condutores para a AP. Na porção central da AP há ocorrência de trends de condutores paralelos às principais estruturas NE-SW (inclusive na área da Mina de Lamego) - Figura 2-a. Este paralelismo também é apresentado na porção $\mathrm{SE}$ da $\mathrm{AP}$, associado às estruturas da deformação D4 (Baltazar \& Zuchetti, 2007). As anomalias do canal ZOFF7 (Figura 2-b) possuem este mesmo paralelismo, podendo indicar zonas sulfetadas geradas pela alteração hidrotermal. Entretanto, a presença de xistos carbonosos e FFBs com bandas ferruginosas condutivas podem tornar esta interpretação ambígua. A Figura 2-c apresenta o mapa de razão Th/K na área piloto, obtido a partir dos dados do aerolevantamento RV1. Nota-se que na porção SE (região do depósito de Roça Grande) e na parte central da AP há forte correlação das orientações das estruturas com os trends de baixos valores de $\mathrm{Th} / \mathrm{K}$, mostrando que o enriquecimento potássico tende a seguir as estruturas. Estas áreas também apresentam boa correlação entre os baixos valores de $\mathrm{Th} / \mathrm{K}$ com os trends de condutores HTEM. Estes resultados indicam que as ocorrências dos condutores podem estar associadas às zonas de alteração hidrotermal com enriquecimento potássico.

A Figura 2-d apresenta o mapa de ISA da AP, obtidos a partir dos dados do aerolevantamento RV1. Esta figura mostra que na região do depósito de Lamego e nas porções Leste e SE (região do depósito Roça Grande) da $\mathrm{AP}$, há forte correlação de corpos magnéticos com a ocorrência dos condutores HTEM, e também com as principais estruturas destas regiões. De fato, observandose o mapa de ISA da AP, nota-se que as estruturas NE-
SW da região da Mina de Lamego e da porção Leste da AP são magnéticas. Da mesma forma, as estruturas da porção SE também se mostram fortemente magnéticas.

Tanto para a região da Mina de Lamego, como para a região do depósito de Roça Grande, estes resultados indicam que as estruturas magnéticas podem estar associadas à disposição das FFBs, ressaltando seu controle estrutural e também sua correlação com as zonas sulfetadas hospedadas por estas rochas. Entretanto, a ocorrência de rochas máficas-ultramáficas na região pode gerar uma interpretação ambígua da análise qualitativa dos dados de magnetometria, necessitando uma análise quantitativa (modelagem direta e inversão). Por isso, para estas duas regiões da AP (detalhadas na Figura 2-a) esta análise é feita em detalhe a seguir.

\section{Depósito de Lamego}

O depósito de Lamego ocorre em uma dobra anticlinal reclinada, isoclinal e cilíndrica, cujo plano axial possui mergulho de 20-30ª para SE (Martins et al., 2016). Possui quatro corpos de minério: Carruagem, Queimada, Arco da Velha e Cabeça de Pedra (Figura 3). O corpo Carrugem é o mais produtivo, com teores da ordem de $62 \%$ (Martins et al., 2016), ocorrendo na junção dos flancos da dobra de Lamego na porção NE, onde ocorre maior volume de silicificação e menor ocorrência de FFBs, maior associação da mineralização aurífera com pirita arsenical e presença de falhas de empurrão e transcorrentes.

A Figura 4-a apresenta o mapa geológico da região da mina de Lamego, a posição de ocorrência dos condutores HTEM e as anomalias de Potássio Anômalo $\left(K_{d}\right)$, Urânio Anômalo $\left(U_{d}\right)$ e Fator $F$ (dentro de três desvios padrão). Nota-se que há uma anomalia de $\mathrm{K}_{d}$ na região do corpo Queimada, alinhado a um trend de fortes condutores (condutância elétrica de classe 7, i.e. maiores do que $50 \mathrm{~S}$ ). Na Figura 4-c, mostram-se também valores baixos da razão $\mathrm{Th} / \mathrm{K}$ na mesma zona do corpo Carruagem, alinhados com o trend de condutores. Notase que o alinhamento dos condutores é paralelo à anomalia positiva do canal ZOFF7, que ocorre sobre todo o flanco SE da dobra de Lamego (Figura 4-b) e às estruturas NE-SW que cortam toda a região da mina. Os altos teores de $\mathrm{K}$ podem estar associados ao maior volume da silicificação no estrangulamento dos flancos da dobra (porção NE, na região do corpo Carruagem), evidenciando sua correlação com a ocorrência dos condutores e, portanto, com a associação da sulfetação mineralizante. O mapa da Figura 4-d apresenta a ISA para a região da Mina de Lamego, retirados do aerolevantamento RV2, e mostra um forte lineamento sobre flanco norte da dobra de Lamego, com orientação para NW-SE.

Para tentar compreender melhor a estrutura da mineralização e ralação com suas rochas encaixantes, foi feita a inversão e integração das fontes magnéticas (que podem causar o lineamento magnético de Lamego) com a modelagem direta de placas de Maxwell para alguns condutores associados ao trend paralelo ao plano axial 
da dobra. As modelagens dos condutores resultaram em placas de Maxwell com mergulho para SE (azimute entre $130^{\circ}$ e $\left.140^{\circ}\right)$, com mergulho variável entre $38^{\circ}$ para o condutor A14 e 20-25 para os outros dois condutores (indicado na Figura 4-a). As profundidades de topo dos condutores podem variar de $1.5 \mathrm{~m}$ até cerca de $40 \mathrm{~m}$.

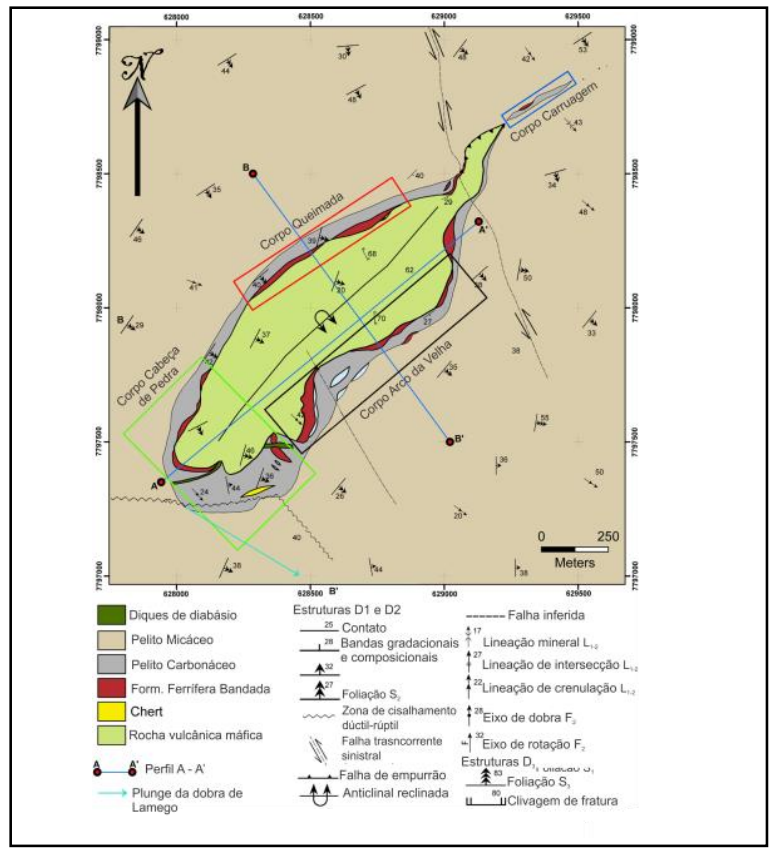

Figura 3 - Mapa Geológico do depósito de Lamego, mostrando os corpos mineralizados auríferos. (Modificado de Martins et al., 2016).

A Figura 5-a apresenta 0 modelo de susceptibilidade magnética resultante da inversão, com valores variáveis entre $0.1-1.2 \mathrm{SI}$. Os resultados da inversão magnética foram integrados com a modelagem direta das placas de Maxwell para os condutores (placas vermelhas) e apresentados nesta figura, mostrando duas isosuperfícies de susceptibilidade magnética geradas a partir do modelo invertido, cujos valores são $0.1 \mathrm{SI}$ (amarela) e $0.35 \mathrm{SI}$ (vermelha). A isosuperfície amarela de $0.1 \mathrm{SI}$ apresenta uma distribuição de susceptibilidade magnética numa geometria de uma superfície côncava, cuja relação com o arcabouço estrutural do depósito, descrito em Martins et al. (2016), ainda não é bem compreendido. Deste modo, necessita de mais estudos geofísicos e geológicos na área.

A isosuperfície vermelha possivelmente indica a posição de ocorrência das FFBs, ou um possível enriquecimento de magnetita hidrotermal nas rochas encaixantes. Se os condutores estiverem associados à sulfetação mineralizante, nota-se na Figura 5-b que a isosuperfície vermelha apresenta um mergulho aproximadamente paralelo a alguns condutores modelados, cujo mergulho varia entre 20-35․ Este resultado pode estar em acordo com a estruturação stratabound da mineralização aurífera associada aos veios de quartzo fumê apresentada por Martins et al. (2016).

\section{Região do Depósito de Roca Grande}

A região do depósito de Roça Grande é marcada pela ocorrência de grandes estruturas de empurrão de direção NE-SW e E-W, de idade Arqueana a Paleoproterozóica (Baltazar \& Zuchetti, 2007), deformadas durante a orogenia Brasiliana. Esta região compreende rochas do Grupo Nova Lima (Figura 6-a), sendo predominante a ocorrência de sequências metavulcânicas máficasultramáficas, sericita-quartzo xistos, quartzitos e FFBs. $\mathrm{O}$ depósito aurífero mais importante da região é a Mina Roça Grande, mas há ocorrência de vários outros depósitos na área, todos alinhados com as estruturas regionais da deformação D4 de Baltazar \& Zucchetti (2007)

O mapa da Figura 6-b apresenta o trend de condutores HTEM alinhados às estruturações regionais e também às zonas de altos valores do canal ZOFF7 (zonas mais condutivas). Estes resultados podem indicar porções sulfetadas geradas pela alteração hidrotermal que causam as ocorrências dos condutores, ou ainda, podem estar associadas a algumas FFBs mais magnéticas, conforme mostram os lineamentos magnéticos da Figura 6-c.

Estas anomalias magnéticas também estão alinhadas com as falhas de empurrão do evento tectônico D4 e associam-se com altos valores da razão Th/K em sua porção central, como mostra a Figura 6-d. Estes resultados possivelmente foram causados por um baixo volume de concentração potássica na porção central da área, embora haja anomalias localizadas e um trend de baixos valores de $T h / K$ na porção $S E$ da região, paralelo às estruturações e em direção ao depósito de Roças Grandes, seguindo também anomalias de $K_{d}$ e Fator $F$ (Figura 6-a).

Para compreender melhor a relação dos condutores com as anomalias magnéticas fortemente correlacionadas com as posições das FFBs, foram feitas modelagens diretas de corpos tabulares magnéticos que tentam simular as respostas das FFBs magnéticas. Após esta etapa de modelagem direta da magnetometria, os resultados foram integrados com os modelos de placas de Maxwell dos condutores HTEM gerados para a área (Figura 7).

A modelagem direta dos corpos tabulares magnéticos considerou as medidas estruturais executadas nas campanhas de campo da equipe do projeto da CPRM. Em média, na porção SE da AP, as FFBs possuem azimute da direção de mergulho entre $135^{\circ}$ e $160^{\circ}$, com mergulho variável entre $35^{\circ}$ e $50^{\circ}$. A susceptibilidade magnética dos corpos foi baseada em valores médios de dados petrofísicos de litologias do QF cedidos pela mineradora AngloGold Ashanti, cujos valores na modelagem variaram entre 0.1 e $0.16 \mathrm{SI}$.

A modelagem direta dos condutores como placas de Maxwell também considerou as medidas de campo e as informações dos depósitos auríferos da região, de modo que as placas condutoras modeladas possuem azimute da direção de mergulho semelhante à dos corpos tabulares magnéticos, mas com ângulo de mergulho 
variável entre $18^{\circ}$ e $25^{\circ}$. Os resultados da modelagem direta dos dados de HTEM e de magnetometria mostram que, se de fato os condutores modelados estão associados à sulfetação mineralizante, estes possuem ângulo de mergulho mais rasos comparado aos das FFBs. Este resultado pode indicar que a mineralização não segue necessariamente o mergulho do plano de acamamento das FFBs (embora ainda sejam stratabounds), mas pode ter sido redirecionada para outras direções preferenciais dos esforços tectônicos, como em estruturas em forma de charuto na parte interna das camadas dobradas das FFBs (Figura 8), em zonas de médio strain, numa fase intermediária da evolução do tectonismo D4 de Baltazar \& Zuchetti (2007).

\section{Discussão e Conclusões}

A Área Piloto (AP) apresenta vários alinhamentos dos condutores, com boa correlação com as principais estruturas regionais, estruturas magnéticas, anomalias do canal ZOFF7 do HTEM, de Fator F, Potássio Anômalo $\left(\mathrm{K}_{\mathrm{d}}\right)$ e razão $\mathrm{Th} / \mathrm{K}$ (valores baixos da razão). Estes resultados indicam forte controle estrutural dos condutores, além de indicar sua possível associação com zonas sulfetadas provenientes do processo de alteração hidrotermal. A integração da magnetometria e gamaespectrometria com os resultados do HTEM mostrou-se uma excelente metodologia para eliminar as ambiguidades interpretativas.

Na região do depósito de Lamego, a inversão magnética, aparentemente, identificou uma distribuição espacial de susceptibilidade magnética em forma de uma superfície côncava, cuja correlação com o arcabouço estrutural de Martins et al. (2016) ainda não é bem conhecida. Deste modo, é necessária a continuidade de estudos integrados de geofísica e geologia. Além disso, a inversão magnética pode ter identificado a posição das FFBs ou então algum enriquecimento de magnetita devido aos processos hidrotermais, permitindo sua correlação com as placas de Maxwell modeladas para os condutores HTEM (Figura 5). Se, de fato, os condutores modelados estiverem associados à mineralização aurífera, o resultado apresentado para o mergulho destes corpos concorda com os resultados de Martins et al. (2016), mostrando que a mineralização possui a mesma direção de mergulho das FFBs (mergulhando entre 20-35ำ para SE).

$\mathrm{Na}$ região do depósito de Roça Grande, os resultados magnetométricos indicaram uma forte correlação das anomalias magnéticas com a posição das FFBs e seu forte controle estrutural. Também mostraram uma boa associação da ocorrência dos condutores HTEM com as estruturas e as FFBs. Entretanto, ao contrário do caso de Lamego, a modelagem direta das placas de Maxwell e dos corpos magnéticos (Figura 7) indicou que, possivelmente, a sulfetação mineralizante de $\mathrm{Au}$ pode não seguir o ângulo de mergulho dos bandamentos das FFBs (cujo mergulho se dá para SE e S-SE, com ângulo entre $\left.35-50^{\circ}\right)$. Aparentemente, seguem direções estruturais preferenciais, possivelmente estruturas mineralizadas em forma de charutos (Figura 8), geradas em zonas de médio strain, durante as fases intermediárias do tectonismo D4 de Baltazar \& Zucchetti (2007), com ângulo de mergulho na faixa de $18-25^{\circ}$ para SE.

\section{Agradecimentos}

Os autores agradecem à companhia AngloGold Ashanti por ceder à CPRM os dados de petrofísica utilizados nas modelagens geofísicas. Em especial, agradecem ao geofísico desta companhia, MSc. Daniel S. Oliveira, pela ajuda para gerar os resultados dos softwares Encom ModelVision e Discovery PA para a modelagem e integração dos dados geofísicos.

\section{Referências}

ALLARD, M. 2007. On the Origin of the HTEM Species. Advances in Airborne Geophysics. In: Proceedings of Exploration 07: Fifth Decennial International Conference on Mineral Exploration, p. 355-374.

BALTAZAR, O. \& ZUCCHETTI, M., 2007. Lithofacies associations and structural evolution of the Archean Rio das Velhas greenstone belt, Quadrilátero Ferrífero, Brazil: A review of the setting of gold deposits. Ore Geol. Rev., 32: 471-499.

MARTINS, B. S., LOBATO, L. M., ROSIÈRE, C. A., HAGEMANN, S. G., SANTOS, J. O. S., VILLANOVA, F. L. S. P., SILVA, R. C. F. \& LEMOS, L. H. A. 2016. The Archean FFB-hosted Lamego gold deposit, Rio das Velhas greenstone belt, Quadrilátero Ferrífero: Evidence for Cambrian structural modification of an Archean orogenic gold deposit. Ore Geol. Rev., 72: 963-988.

ROBERT, F. \& POULSEN, H. 2001. Vein Formation and Deformation in Greenstone Gold Deposits. In: RICHARDS, J.P. \& TOSDAL ,R.M. (eds.) Structural Controls on Ore Genesis. Society of Economic Geologists, Reviews in Economic Geology, 14: 111 - 155.

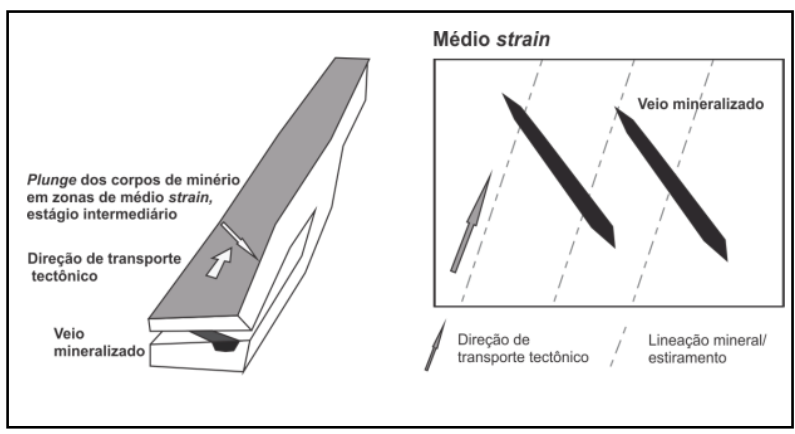

Figura 8 - Relações geométricas entre elementos estruturais e corpos de minério (eixos de dobras e boudins). Com o aumento progressivo da deformação estes corpos tendem a rotacionar para o paralelismo com a direção de transporte tectônico (Adaptado e modificado de Robert \& Poulsen, 2001). 


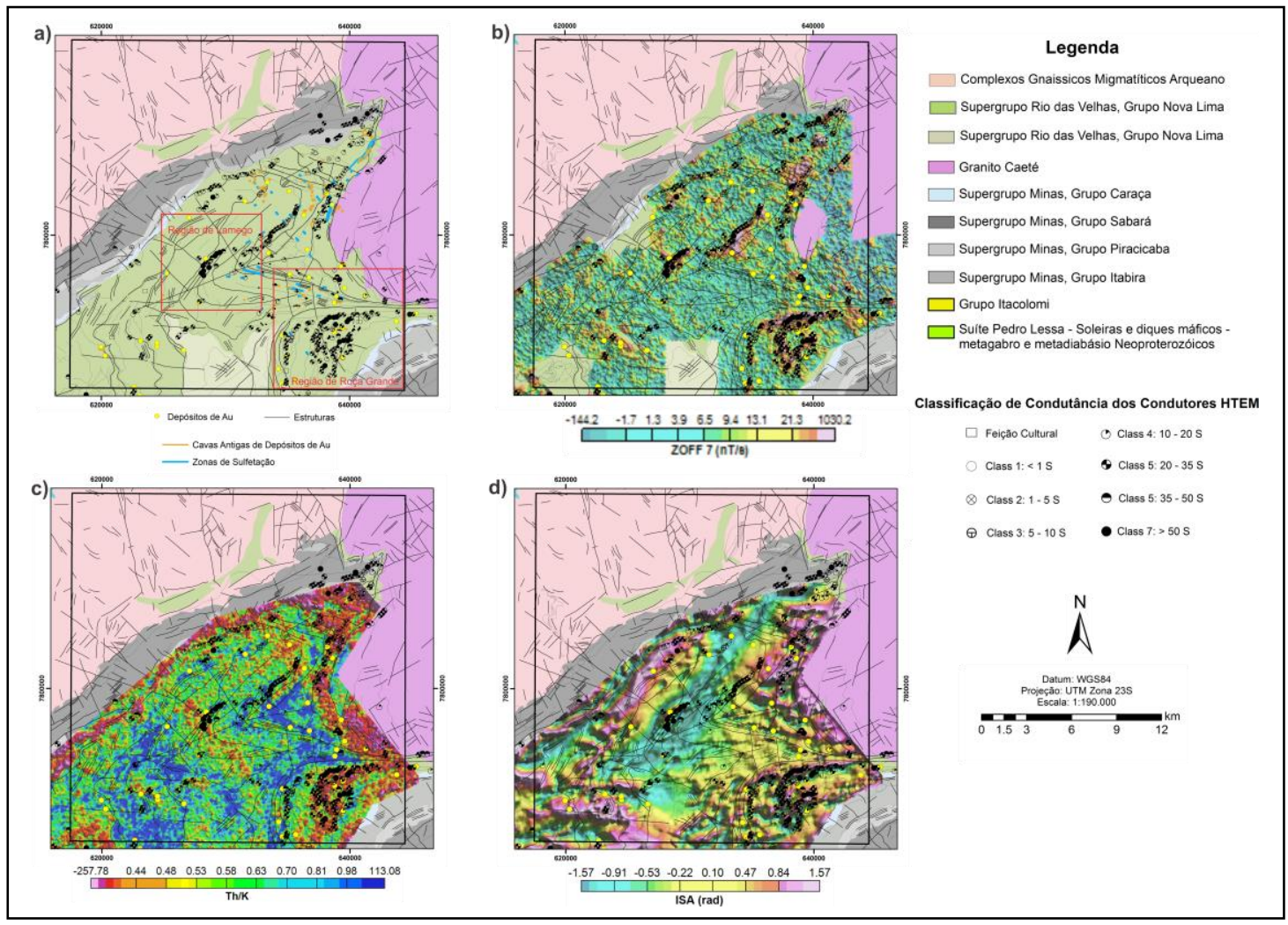

Figura 2 - Mapas temáticos da AP. (a) Mapa geológico. (b) Canal ZOFF7 do HTEM. (c) Razão Th/K. (d) ISA.

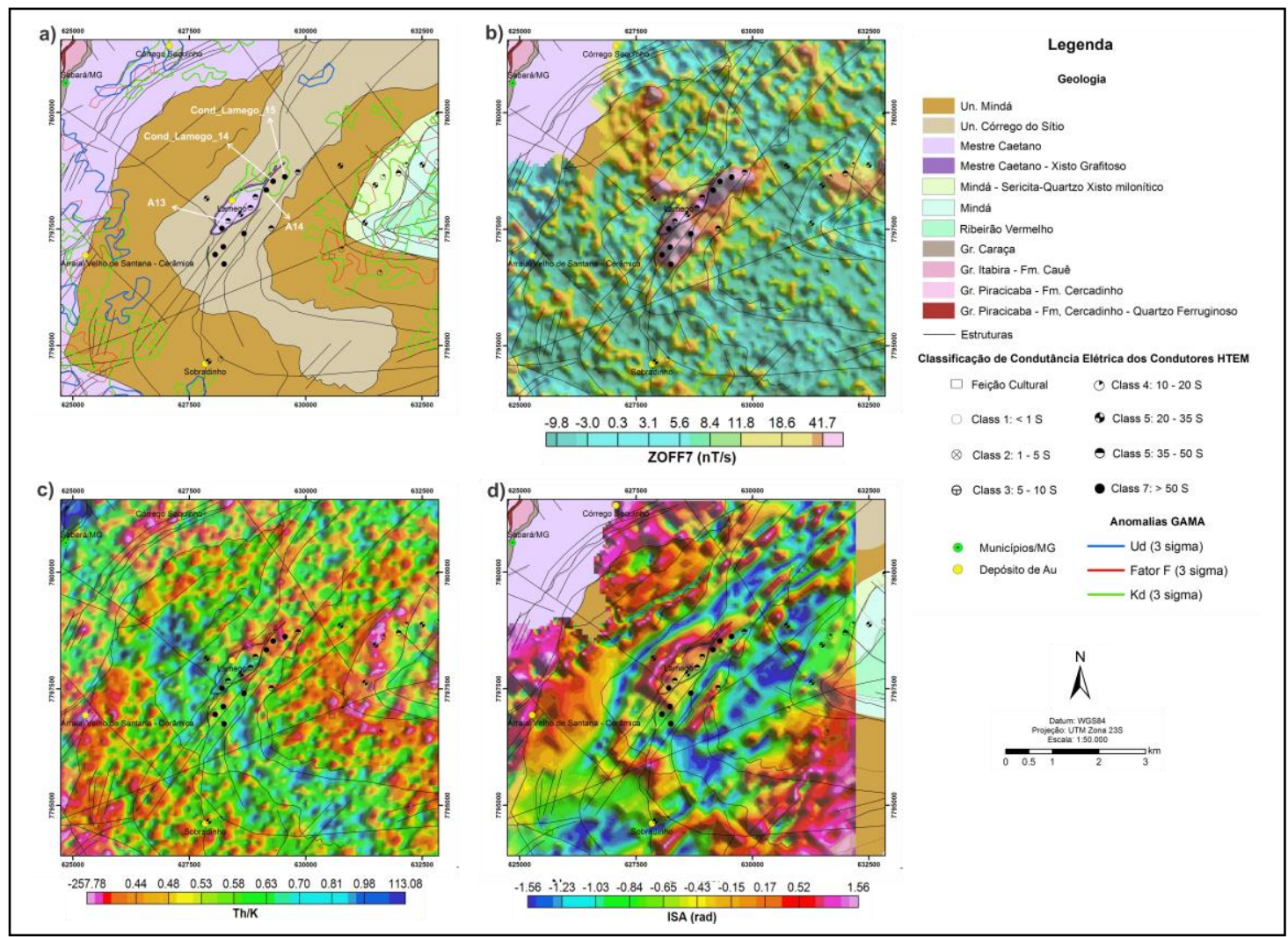

Figura 4 - Mapas temáticos da região do depósito de Lamego. (a) Mapa geológico. (b) Canal ZOFF7 do HTEM. (c) Razão Th/K. (d) ISA. As setas brancas indicam os condutores HTEM modelados. 


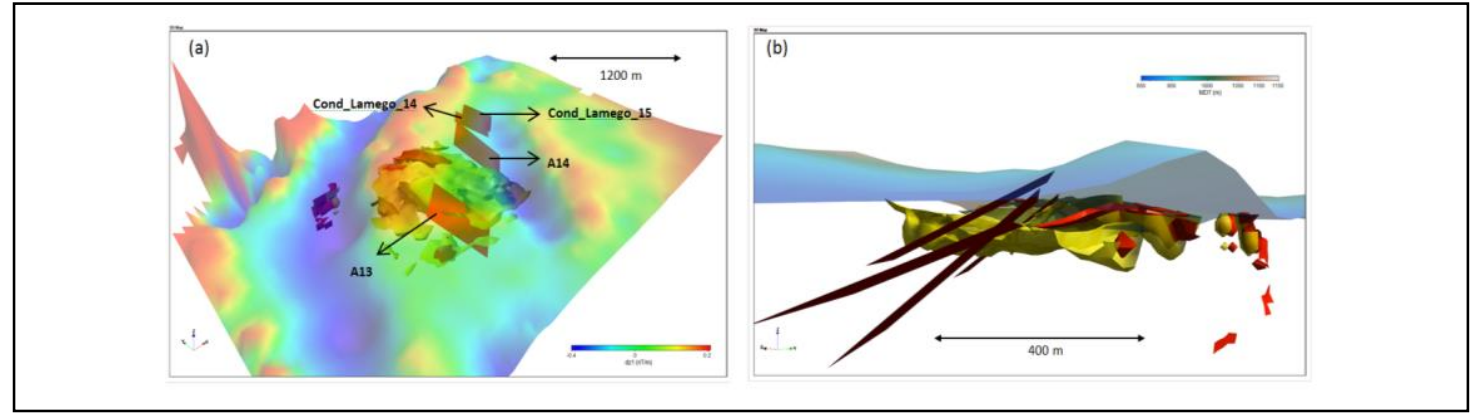

Figura 5 - Integração do modelo magnético invertido (isosuperfícies) com as placas de Maxwell modeladas para os condutores HTEM (placas vermelhas). As isosuperfícies apresentadas possuem susceptibilidade magnética de $0.1 \mathrm{SI}$ (amarela) e $0.35 \mathrm{SI}$ (vermelha). O sistema de eixos cartesianos indica a orientação dos modelos, sendo y para o Norte, x para Leste e z indica a altitude. (a) Derivada Vertical da região sobreposto aos modelos. (b) Vista lateral dos modelos, com visada para NE e integrado com o Modelo Digital de Terreno.
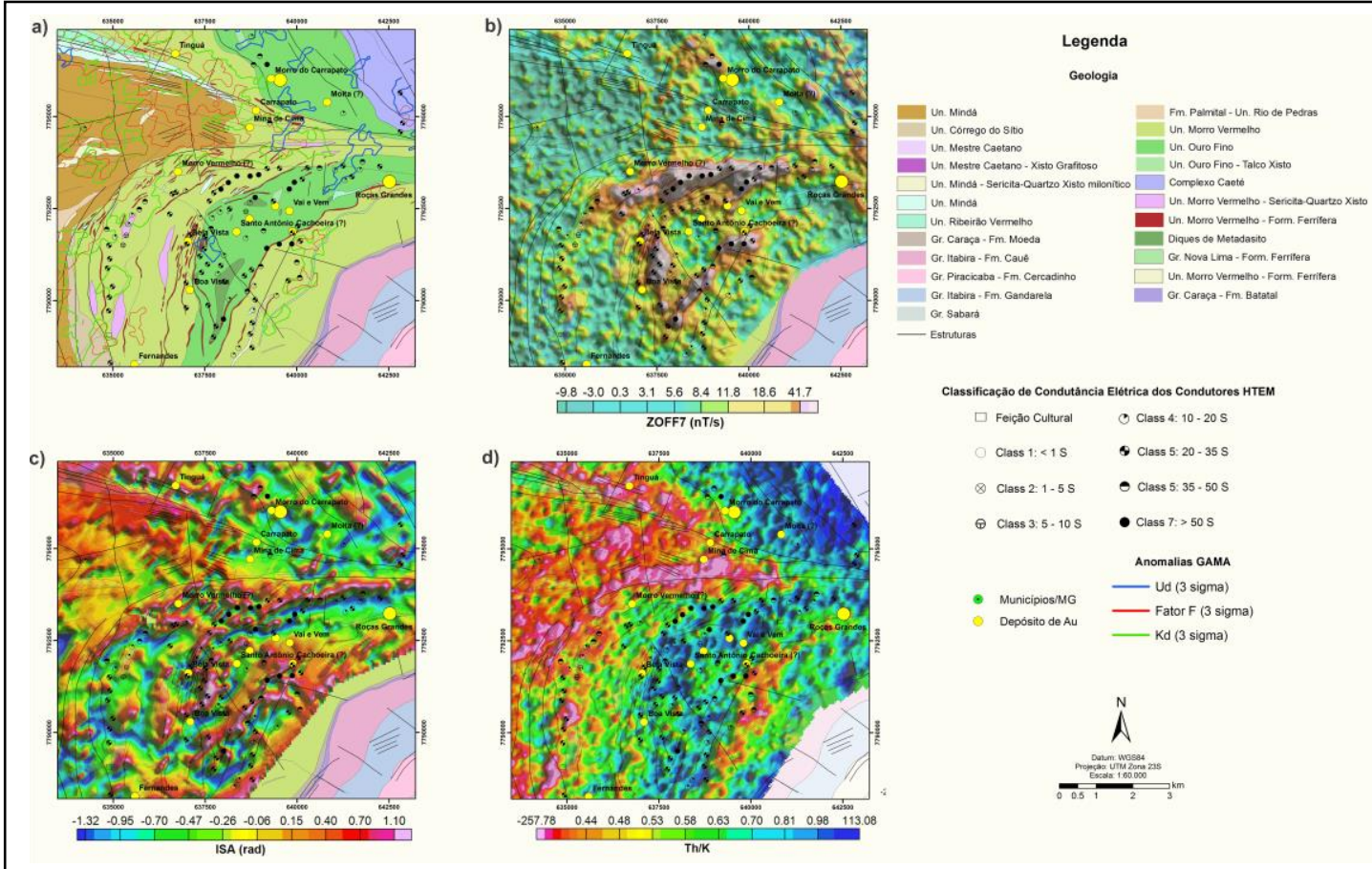

Figura 6 - Mapas temáticos da região do depósito de Roça Grande. (a) Mapa geológico. (b) Canal ZOFF7 do HTEM. (c) ISA. (d) Razão Th/K.
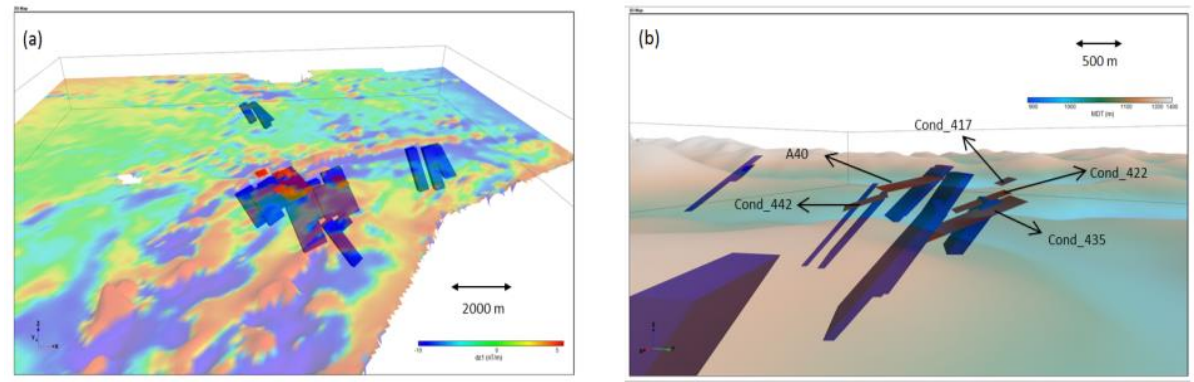

Figura 7 - Representação 3D da integração dos modelos de corpos tabulares magnéticos (prismas azuis) com os modelos das placas de Maxwell (placas vermelhas) na porção SE da AP. (a) Com sobreposição da derivada vertical, com visada para N-NE. (b) Detalhe com sobreposição do Modelo Digital de Terreno, com visada para NE. 